\title{
LA VANGUARDIA ATALAYISTA \\ Y LA OBRA DE \\ CLEMENTE SOTO VÉLEZ
}

POR

RAFAEL CATALÁ

Una breve mirada al horizonte literario puertorriqueño de los años veinte y treinta revela que la poesía joven ya andaba en busca de nuevas formas de expresión. Por ejemplo, el pancalismo y el panedeísmo que inicia Luis Lloréns Torres en 1913, ${ }^{1}$ y el diepalismo creado por José de Diego Pardó y Luis Palés Matos en 1921 muestran estas inquietudes. Otra de las voces que apuntan hacia la necesidad de un cambio transformador es Evaristo Ribera Chevremont, quien en abril de 1924 publica en la revista Puerto Rico Ilustrado el ensayo "El hondero lanzó la piedra" (233-235). En este artículo apunta la necesidad de "una revolución lírica" que destruya "todo lo que hasta aquí se ha hecho" (233-235). Habla de la necesidad de romper con la métrica y la rima, ataca el soneto modernista y la artificialidad modernista ("pieza que fue flor de orfebrería y pensamiento en Darío, sol de imágenes y rarezas en Herrera y Reissig ... pero que ha sido deformado por ... Francisco Villaespesa"). Evaristo Ribera Chevremont pide que se desnaturalice el poeta para de esta forma llegar a la Naturaleza; propone destruir símbolos modernistas, como el ruiseñor y el cisne, y proclama la utilización de símbolos menos exóticos y más a tono con la realidad del contexto en que el poeta está inscrito, la rana, por ejemplo, "esa joya de porcelana verde prendida al seno oscuro de las charcas" (233-235).

El 29 de noviembre del mismo año, en la misma revista publica "Llamamiento". Aquí advierte que el estudiantado es el grupo más al tanto de las nuevas ideas y propone mirar hacia España, Francia e Italia, donde una revolución artística y literaria está teniendo lugar. Elogia los logros literarios de Huidobro y propone que "Puerto Rico no se debe quedar rezagado en este movimiento que tiene en expectación al mundon (236-237).

La renovación que propone Ribera Chevremont en este ensayo no es tan totalizante, esto es, no propone una renovación que nazca del ser americano, sino de la imitación que él critica, ya que nos pide que miremos hacia España,

${ }^{1}$ Luis Hernández Aquino, Nuestra aventura literaria (San Juan: Ediciones de la Torre, 1966) 11. 
Italia y Francia. Más adelante, en el mismo ensayo, propone un idealismo elitista respecto al arte. Él sueña con un "arte desinteresado, virtuoso ... pleno de hermosuras ... un arte que sea arte dentro del verso y la prosa de espaldas al aplauso y al vocerio de las masas inconscientes". Los modelos que propone son extranjeros: "Jean Cocteau, Morand y Apollinaire, representan en Francia el arte de espaldas al público". Con estos modelos en mano flagela el establecimiento literario puertorriqueño, "Aqur el menor poetastro se cree un Homero: cualquier pintamonas, un Leonardo de Vinci ... Rechazad esa literatura de hombre-mono, de antropopiteco primitivo, esa literatura de caverna ..."(236238).

Ribera Chevremont propone una manera sofisticada de imitar imitando a la vanguardia europea, la nueva Europa, no la vieja que veníamos imitando anteriormente. No obstante, este poeta apunta y exige un cambio en la literatura puertorriqueña.

Las bases para ese cambio radical que exigía la nueva poesía puertorriqueña ya estaban en su lugar. Hostos había apuntado hacia una expresión autóctona en el proceso educativo. Betances habia hecho otro tanto al apuntar que debíamos:

conspirar, porque sin escuelas, sin colegios, ni más medios de instrucción que los que puedan proporcionarnos en el extranjero nuestros propios recursos, vemos a la juventud languidecer en medio de la común ignorancia ... .2

En realidad, Ribera Chevremont había tenido que ir a España a encontrar nuevos aires que renovaran su poesía, cumpliendo así lo que Betances había denunciado. La obra de Betances, como la de Hostos, era la raíz de una verdadera transformación; no la transformación vía reflejo de lo europeo. La verdadera transformación, de acuerdo con Hostos y Betances, está en el desarrollo de lo propio. Esto es no sólo el desarrollo de una nueva literatura,sino que van mucho más allá; es además el desarrollo de una teoría y praxis generadora de todas las fuerzas motrices de la cultura. De aquí que Hostos escogiera la educación como centro teórico de sus operaciones intelectuales. La falta de la cultura puertorriqueña, e hispanoamericana en general, ha sido no formar una escuela a partir del trabajo de Hostos en este respecto. Un corpus teórico no nace por lo regular de un solo pensador, sino que generaciones posteriores toman esos postulados originales y construyen, a partir de ellos, la teorfa que luego genera una praxis cultural.

Martí, por su parte, en "Nuestra América" (1891) y en otros muchos ensayos había expuesto, como Hostos y Betances, una visión americana de nuestra literatura. En la Revista Venezolana del $1^{\circ}$ de julio de 1881, dice que hay que:

2 M. Maldonado-Denis, Betances: Revolucionario Antillano (Río Piedras: Editorial Antillana, 1978) 30-31. 
descubrir con celo de ge6grafo los origenes de esta poesía de nuestro mundo, cuyos cauces y manantiales genuinos, más propios y más hondos que los de poesía alguna sabida, no se esconden por cierto en estos libros pálidos y entecos que nos vienen de tierras fatigadas. ${ }^{3}$

Las bases teóricas de la renovación cultural hispanoamericana están expuestas en la obra de estos pensadores. Su visión no es local sino continental. Martí apunta que no habrá literatura hispanoamericana "hasta que no haya Hispanoamérica" (Ideario 35).

Ribera Chevremont propone en su ensayouna renovaciónliteraria, autóctona pero mirando hacia el extranjero, cosa que Hostos, Martí y Betances rechazan, ya que ellos han visto el proceso sicológico-cultural desde sus profundidades, $y$ no superficialmente como podemos descubrir en Ribera Chevremont. Si se hace lo que propone este último se repite lo que Martí ha descrito en "Nuestra América" (1891) con respecto a la vida política:

Éramos una máscara, con los calzones de Inglaterra, el chaleco parisiense, el chaquetón de Norteamérica y la montera de España ... Éramos charreteras y togas, en paises que venian al mundo con la alpargata en los pies y la vincha en la cabeza (Ideario 40).

Aquí la diferencia entre laimitación de una vanguardia a la creación de una vanguardia. La vanguardia cultural y literaria lo eran ya Hostos, Marti y Betances. En ellos no era posible imitar una vanguardia literaria europea. Ellos eran la vanguardia -eran el producto sincrético de varias culturas americanas y europeas, pero del pasado habían generado una nueva cultura: la criolla. De la conciencia de esta avanzada cul tural partian estos pensadores, por esto ya no tenían que mirar hacia Europa, sino mirarse a sí mismos y caminar desde su realidad hacia el futuro (Ideario 38 ).

Podría decirse que Ribera Chevremont no tuvo acceso a la obra de Hostos o que estos textos no se encontraban en el medioinmediato de Ribera Chevremont, pero un artículo bibliográfico de Antonio S. Pereira, "Contribución al estudio de Hostos", publicado en Alma Latina entre agosto de 1930 y julio de 1931, muestra la existencia de ellos. ${ }^{4}$ Ahora, la mera existencia de los textos no explica el fenómeno de que no hayan sido leídos y/o nombrados por un autor específico. En América el proceso consciente e inconsciente de la dependencia cultural ha hecho que el intelectual americano mire hacia afuera antes de mirar hacia sí mismo. Además, nuestros propios textos tienen poca difusión, mientras que los textos europeos, la producción cultural europea, tienen una difusión y distribución

${ }^{3}$ Hans Otto Dell, El ideario literario de José Martı (La Habana: Casa de las Américas, 1975) 34.

${ }^{4}$ M.Maldonado-Denis, Eugenio M. de Hostos , sociólogoy maestro (Río Piedras: Editorial Antillana, 1981) 208. 
garantizada. La complejidad de estas relaciones de dependencia no nos permite acusar a Ribera Chevremont de no haber leído textos que se encontraban en su medio ambiente inmediato. Ahora, lo importante es mostrar la existencia de ellos y el retraso cultural que su ignorancia conlleva.

Los atalayistas vienen a cristalizar una visión más concreta de esta necesidad de renovación. El primer manifiesto atalayista se publica en el periódico El Tiempo, el 12 de agosto de 1929. Lo firma Clemente Soto Vélez. Aqui encontramos muchas ideas ya esbozadas por Ribera Chevremont, tales como el rechazo de la rima y del metro, pero hay un desafio más atrevido; ataca muchos de los lugares sagrados de la conciencia estancada del establecimiento literario y cultural. Por ejemplo, "un descarrilamiento de trenes es diez mil veces más bello que los éxtasis de Santa Teresa".

El movimiento literario atalayista proporciona una oportunidad para pensar y cuajar una práctica cultural. Esto es, la literatura entronca con los diferentes elementos que la componen. El ensayo de Graciany Miranda Archilla, "Hacia un arte político" publicadoen Alma Latina en junio de 1931 discute laimportancia del compromiso en la literatura. Este ensayo parece que fue escrito en el momento en que los atalayistas no tenían una dirección definida, pues su autor, uno de los fundadores del atalayismo, acusa a los atalayistas de ser cómplices y propulsores de la ignorancia estética, y apunta que el atalayismo debe comenzar por conocerse a sí mismo pues aún "piensa con pensamiento ajeno y, por ende, su manifestación es congruente a la manifestación arcaica de los Becquer y los Heine". Una cosa que preocupa grandemente a Miranda Archilla es la "ausencia de la unidad política en el poema de vanguardia", ya que establece paralelos con la producción literaria "clasicista y la nueva". Miranda asevera que hasta ese momento permanecen "apegados al tronco secular e infundadamente [se llaman] vanguardistas, cuando la vanguardia no es un hecho literario y sí un hecho político". Esta toma de conciencia cultural culmina entonces en una "exaltación ética, filosófica y artística de los individuos". ${ }^{6}$ Miranda Archilla entronca con la praxis introspectiva de Hostos, Marti y Betances en este ensayo.

En el mismo artículo encontramos una nota al calce que parece demostrar la función de la praxis reflexiva de este artículo. Miranda Archilla anota que su acusación de arte reflejo y de falta de definición "ya no cuadra al Atalayismo" puesto que éstos ya "reconocen la necesidad de impulsar el sentido político del poema nuevo y se imponen la tarea de cumplir con el minuto estético-político". Los atalayistas, en efecto, unieron sus fuerzas al movimiento de independencia que dirigía Pedro Albizu Campos. Debido a esto Clemente Soto Vélez fue sentenciado a siete años de prisión, y luego fue desterrado.

\footnotetext{
${ }^{5}$ El Tiempo (Puerto Rico, 12 de octubre de 1929) 4.

"Graciany Miranda Archilla, "Hacia un arte político". Alma Latina 11 (San Juan, junio de 1931).
} 
Tal parece que lo que se funde en la mente de este movimiento es el concepto de cultura que abarca todos los elementos del devenir intelectual de un pueblo. El poeta, como parte de este complejo devenir, comienza a apropiarse de todos los elementos del proceso de individuación nacional. Esta catálisis creadora no sólo renueva las letras, sino que ayuda a la toma de conciencia cultural respecto a otros niveles de la sociedad. Estos procesos reflexivos dan lugar a otros trabajos de análisis con miras al futuro, como el trabajo de Fernando González Alberty “La vanguardia en Puerto Rico", que salió publicado en Alma Latina en febrero de 1933. En él González Alberty explica que la reacción anti-atalayista ha aminorado, y comienza a explicar los movimientos literarios y los poetas que precedieron al atalayismo. Dice González Alberty que el atalayismo es único porque éste fue el único que adquirió "la clave del movimiento continuo" y que logró imponer sus doctrinas. Más adelante, recorre brevemente varias escuelas y poetas que precedieron al atalayismo. De Lloréns Torres, Luis Palés Matos, y José de Diego Padró, apunta que en sus respectivas obras hay "esporádicamente atisbos vanguardistas, pero ninguno de estos vates se abraza plenamente a los estandartes de la nueva lírica". Él los considera como tres grandes figuras de la literatura puertorriqueña. Del noísmo, dice González Alberty, que "surgió preñado de laudables propósitos novadores, pero su existencia fue superlativamente efímera". De Evaristo Ribera Chevremont apunta que su obra es "originalísima, rica en imágenes inéditas, ... cultiva el eclecticismo" pero sus "convicciones estéticas no lo han dejado desprenderse de las tradicionales rémoras del metro y la rima. Pero aún en sus creaciones clásicas destaca su vigoroso estro de aeda moderno. Es un gran poeta. ${ }^{7}$

Este artículo nos proporciona la visión crítica desde adentro del movimiento mismo, ya que él fue uno de los atalayistas, y nos está hablando de una visión crítica desde el presente. Esto es cómo los atalayistas ven su pasado inmediato y cómo ven la contribución de su vanguardia literaria a las letras y cultura puertorriqueñas.

El atalayismo cuaja toda una serie de vectores culturales en una nueva y fresca expresión literaria. La ética y la estética se aúnan, formándose así un vector cultural complejo y de pujante fuerza. Miranda Archilla lo expresa de este modo:

La Creación ... determina el carácter del ser pensante. Ésta, por lo visto, está reñida con la limitación, con la singularidad; comulga con la generalización. En sí el Hombre se nos presenta como la pluralización artística del Todo.

Ahora bien, si el Hombre es el producto más político de la Creación, siendo a su vez la pluralización artística del Todo, debemos tener en mente que no puede concebirse un Arte Literario y que la unidad política afianza la unidad poética del conjunto. ${ }^{8}$

\footnotetext{
${ }^{7}$ Fernando González Alberty, "La vanguardia en Puerto Rico". Alma Latina 31, febrero de 1933, sin paginar.

"Miranda Archilla, "Hacia un arte..."
} 
Por esa misma fecha, el 27 de julio de 1929, Alfredo Margenat publica en $E l$ Imparcial el artículo "El poema atalayista" donde comienza a exponer algunos elementos literarios de la nueva visión y conecta la vanguardia atalayista con otras vanguardias europeas. Unos meses más tarde, el 12 de agosto de 1929, Clemente Soto Vélez publica en El Tiempo el primer "Manifiesto Atalayista" expresando el rechazo del metro y de la rima, aseverando que los atalayistas quieren "explotar la cantera del librepensamiento para construir nuevas carreteras" para la electricidad. Apunta hacia el porvenir libertario, y cuaja esta nueva visión con frases atronadoras, como el "descarrilamiento celeste de una monja”.

El nacionalismo es un común denominador en los atalayistas. Éste es un sentimiento difuso en ellos y carecen de un programa político a seguir. Albizu Campos le proporciona al atalayismo el esquema político que dará impulso y cohesión a este movimiento literario. Albizu Campos es, por tanto, un elemento catalítico importantísimo para el movimiento atalayista ya que le proporciona a este movimiento lo que le falta a otros: un programa político renovador. Este elemento completa la ecuación que hace al atalayismo una vanguardia literaria en las letras puertorriqueñas. Esto no quiere decir que los otros movimientos literarios no tengan programas, pero el atalayismo fue el que llegó a un acuerdo con Albizu Campos y fueron atalayistas como Soto Vélez quienes, con Albizu fueron a la cárcel en aras de la República puertorriqueña.

Si tratamos de ver al atalayismo dentro del contexto total de la sociedad puertorriqueña nos encontramos con un problema mucho más complejo, que este trabajo se limitará a apuntarlo solamente, ya que nos lleva fuera del marco del mismo: ¿Cuál es la relación de los atalayistas con el movimiento obrero en ese momento histórico? ¿Qué diferencias hay entre el nacionalismo atalayista y el nacionalismo del movimiento obrero?

Con esta breve visión de algunos vectores literarios comunes a los atalayistas, mutatis mutandis, pudimos observar un movimiento hacia la autoctonalización de la literatura, sin negar las contribuciones de otras culturas, perointegrándolas en su práctica literaria -a la manera martiana: "Injértese en nuestras Repúblicas el mundo; pero el tronco ha de ser el de nuestras Repúblicas".

Por esa época se publicaban en Alma Latina artículos sobre el místico hindú Krishnamurti. ${ }^{10}$ Esta publicación la dirigía Miranda Archilla y era un vocero importante de los atalayistas. Krishnamurti estuvo asociado en una etapa

\footnotetext{
๑ José Martí, "Nuestra América". Obras Completas III. Ed. Jorge Quintana (Caracas, 1964) 108.

${ }^{10}$ Entre otros tenemos los números de abril, mayo, junio y julio de 1936. La publicación de libros teośficos es mucho más temprana. La obra del teósofo Leadbeater, por ejemplo, fue publicada en 1912, y la obra de Helena Petrovna Blavatsky, fundadora de la teosofía (Nueva York, 1875), data de 1877. Isis Unveiled fue publicada en 1877, The Secret Doctrine, en 1888, The Key to Theosophy, en 1889, The Voice of Silence, en 1889, y Glossary of Theosophical Terms en 1888-91.
} 
temprana de su vida a la teosofía. Este movimiento religioso-filosófico se basa en la investigación y descubrimiento de uno mismo y de la relación del ser humano con sus diferentes dimensiones físicas, mentales y espirituales. Así como la relación del ser humano con el espacio que lo circunda y que le da vida. ${ }^{11}$

Escalio, ${ }^{12}$ primer libro de Clemente Soto Vélez, parece haber sidoinfluenciado por este movimiento religioso. La teosofía enseña acerca de la organización de la materia en diferentes etapas de la evolución del ser (ego). ${ }^{13}$ Escalio toma una dirección similar con respecto a la organización de la materia, como por ejemplo, "la materia organizada en fuerza inclinada directamente a la absorción, eso es el imperialismo. En este punto radica el desequilibrio universal" (Escalio 10) En esta cita el autor nos muestra la polaridad materia-espíritu, e identifica a la primera con el imperialismo y a la segunda con su valor superior.

Otro aspecto importante de Escalio es la utilización de colores para mostrar procesos gradatorios del devenir evolutivo de la conciencia humana. Estos mismos principios caracterizan a la teosofía. Ahora, lo que ocurre es que el autor adopta los principios gradatorios de este sistema filosófico-religioso a los que da un valor personal que no coincide necesariamente con su fuente referencial. Han sido transformados por el proceso y la circunstancia creadora de este poeta. ${ }^{14}$

El concepto del tiempo aúna Escalio con la teosofía. Soto Vélez apunta que "En la escala sideral del espíritu, el tiempo no existe" (Escalio 24), y Leadbeater en su Texto de teosofía nos dice que en el mundo espiritual el tiempo no existe como existe en el mundo físico. ${ }^{15}$

En el atalayismo y en la obra de Soto Vélez encontramos un rechazo a toda autoridad. En Escalio encontramos un llamado a la revolución total de la conciencia humana. Hay que comprender este llamado dentro de la tradición teosófica puertorriqueña, pues la teosofía es un subtexto de este momento histórico y literario. Escalio no propone un programa de cómo llevar a cabo esa revolución de la conciencia, pero, si tenemos en cuenta el programa teosófico que influye en esta obra, podemos percibir algunas huellas que nos servirán de guía para vislumbrar el programa en la estructura de profundidad de este texto. En un artículo del Dr. José D. Montenegro sobre Krishnamurti, de esa época, en Alma Latina, se habla del rechazo a toda autoridad:

Por eso Krisnamurti [sic] dice: "Mas, para mi, toda autoridad, tanto objetiva como subjetiva, es igual, porque autoridad implica modelo, imitación, control, acondicionamiento" ${ }^{16}$

\footnotetext{
${ }^{11}$ G.W. Leadbeater, A Textbook of Theosophy (Madras: The Theosophical Publishing House, 1912) 1-8.

12 Clemente Soto Vélez.,Escalio (San Juan: Editorial Puerto Rico Libre, 1937).

${ }^{13}$ Leadbeater, Textbook..capitulos III y IV.

${ }^{14}$ Leadbeater, Textbook...cap. V.

${ }^{15}$ Leadbeater, Textbook.... 75.

${ }^{16}$ Alma Latina ( San Juan, mayo de 1936) 40.
} 
Este libertarianismo hay que comprenderlo dentro del contexto de la teosofía y no como un llamado al caos. En la teosofía, como en cualquier otro proceso de la conducta humana, se busca un orden. Krishnamurti desecha toda internalización intelectual de esquemas externos - consciente o inconscientemente- en la búsqueda de una expresión u orden espontáneo que emerja de la conciencia del individuo - si juzgamos por la vida de este místico, que pasó muchos años de disciplina, para luego rechazar la disciplina misma. Quien internaliza un proceso y después lo rechaza, ha llegado a una transformación de su propia conciencia. Este rechazo es, por tanto, diferente al rechazo de la persona que, sin haberse sometido a este proceso, rechaza la disciplina. La conducta que surge de la práctica extensa del iniciado es una conducta que es producto de un proceso reflexivo y no de la inexperiencia. Esta es la conducta que en cierta forma se puede vislumbrar en Escalio. Esta obra emerge de un proceso de concientización, aunque no llega a ofrecer un programa explícito de cómo revolucionar la conciencia humana. Ahora, si leemos Escalio dentro del contexto religioso, filosófico, y social en que este texto está inscrito, podemos entonces leerlo de acuerdo con los esfuerzos liberadores de su autor.

Debo anotar que en este caso el texto de Soto Vélez antedata el artículo de Montenegro, pero la comunalidad de ideas creada por la saturación de textos e ideas en un periodo dado lleva a razonamiento y conclusiones afines. Ya para esa fecha la teosofía había enraizado en el contexto de la Isla. Tan es así que hoy día subsiste una Fundación Krishnamurti en Puerto Rico, y el último libro de Alfredo Margenat —otro fundador del atalayismo-en 1978 es de corte místicoreligioso, Así habló el Maestro.

En la relación de textos en su contexto cul tural Escalio presenta otros puntos de tensión, tales como la prosa llena de reminiscencias modernistas, de los que esta obra de la juventud del autor no pudo librarse del todo - aún cuando en mayo de 1929 en su poema "El Cisne de Rubén", publicado en El Tiempo comienza a criticar el modernismo. ${ }^{17}$

El idealismo etéreo del modernismo que hizo famoso a Darío se contrapone en Escalio con un idealismo revolucionario. Este último es el proceso sincrético de los ideales revolucionarios del movimiento independentista puertorriqueño - desde Hostos hasta Albizu Campos- con la teosofía. Hay que observar que este movimiento religioso, dentro del contexto cultural de la época, significó para ciertos segmentos de la sociedad puertorriqueña una opción de ruptura con la religión establecida y hegemónica, la católica. La teosofía suplió, además, respuestas a muchas preguntas que el catolicismo no podía contestar por su dogmatismo.

Diecisiete años más tarde Soto Vélez escribe Abrazo interno (1954); le siguen Árboles (1955), Caballo de palo (1959), y La tierra prometida (1979). Aesta serie de textos la he denominado la etapa dialéctica de la obra de Soto Vélez. El

${ }^{17}$ El Tiempo (Puerto Rico, 12 de agosto de 1929) 4. 
proceso dialéctico comienza con una visión de la realidad en cambio continuo o evolutivo -recordemos lo que apuntó González Alberty, que el atalayismo fue el único movimiento que adquirió "la clave del movimiento continuo". En este proceso se pasa, a veces, de tesis a antítesis a síntesis, y se llega al materialismo dialéctico, donde la naturaleza se percibe como una totalidad en que todos los componentes de ella están orgánicamente unidos y relacionados. James Romano describe este transcurrir poético como el paso de la anáfora dialéctica a la dialéctica anafórica. ${ }^{18}$ En el trabajo de este crítico se demuestra cómo, en Árboles, Soto Vélez comienza a utilizar la anáfora para estructurar un proceso dialéctico. En Caballo de palo estas estructuras se sintetizan en la humanidad al objetivar y universalizar el nombre "Clemente Soto Vélez", que pudo haber nacido en cualquier lugar del mundo. El yo personal se transforma en el yo colectivo y comienza a conocerse a sí mismo en todos los seres humanos, ${ }^{19}$ a través de la anáfora dialéctica: "Lo conoci", que se repite constantemente en el texto seguido de las maneras en que ese sujeto universal y concreto es conocido.

Este proceso de conocerse nos remite a Escalio y a la teosofia, ya que ambos proponen el conocerse a sí mismo como la mejor forma de conocer el mundo. En este acto de conocerse a sí mismo comienza el proceso transformador de donde surgen el nuevo hombre y la nueva mujer. En Escalio tenemos una frase que explica este concepto dialéctico: "Es necesario que la periferia y el centro se den la mano" (42). Esta transformación -o síntesis-se realiza en Caballo de palo, y se expresa lingürsticamente al mutar la " $\mathrm{C}$ " en " $\mathrm{K}$ " en el nombre Clemente.

La tierra prometida comienza también con la estructura anafórica "la tierra prometida es" y "la tierra prometida no es", dándonos así un juego de tesis y antítesis, de "constante re-definición a través de modificaciones continuas" (67). La tierra prometida representa el proceso evolutivo de la anáfora dialéctica a la dialéctica anafórica (67).

Para finalizar, debemos anotar que uno de los aspectos más importantes de la obra de Soto Vélez es su capacidad transformadora. En Escalio la teosofía se convierte en una revolución de la conciencia humana que lucha contra el imperialismo, y en el resto de su obra encontramos un proceso constante de transformación en un devenir de estructuras dialéticas. Este constante devenir le da una cualidad innovadora a los textos que fueron objeto de este breve estudio.

\footnotetext{
${ }^{18}$ James V. Romano, Clemente Soto Velez: Texto y Contexto. Tesis de Maestría (New York: Columbia University, Departamento de Español y Portugues, 1983).

10 Rafael Catalá, "La evolución del pensamiento en tres poetas del Caribe: Manuel Navarro Luna, Clemente Soto Vélez y Pedro Mir". Literatures in Transition: The Many Voices of the Caribbean Area. (Maryland: Hispamérica \& Montclair State College, 1983).
} 
